\title{
Becoming a congenital heart surgeon in the current era: Realistic expectations
}

\author{
Charles D. Fraser, MD \\ From the Division of Congenital Heart Surgery, Texas Children's Hospital, Baylor College of Medicine, Houston, \\ Tex. \\ Disclosures: Author has nothing to disclose with regard to commercial support. \\ Received for publication Feb 23, 2016; accepted for publication Feb 25, 2016; available ahead of print March 23, \\ 2016. \\ Address for reprints: Charles D. Fraser, MD, Division of Congenital Heart Surgery, Texas Children's Hospital, \\ Baylor College of Medicine, 6621 Fannin St, Houston, TX 77030 (E-mail: charlesf@bcm.edu). \\ J Thorac Cardiovasc Surg 2016;151:1496-7 \\ $0022-5223 / \$ 36.00$ \\ Copyright (c) 2016 by The American Association for Thoracic Surgery \\ http://dx.doi.org/10.1016/j.jtcvs.2016.02.054
}

At an early phase of my cardiothoracic residency, a "wise" senior cardiac surgeon once told me, "pediatric heart surgery is not hard to do, it is hard to get to do." This was a widely quoted maxim of the time, and I did not quite know what to do with the information. It might have been partially true then, when expectations for surgeon performance in the field were variable, rapidly evolving, and frankly not all that high. The maxim is, decidedly, not true now; pediatric heart surgery in the current era is not only hard to get to do, it is hard to do. This is a primary premise that I consistently bring to the conversation when aspiring young congenital heart surgeons come to me for advice and counsel about this career choice. It is extremely unwise to pursue a career in congenital heart surgery without a significant amount of soul searching and careful consideration of the realities of the pathway. One frequently asked question is "how do I know I can do the surgery?" My answer is not reassuring: I genuinely do not know how to tell in advance whether one will succeed as a congenital heart surgeon. How does one put together the elements of technical skill, judgment, diagnostic acumen, physical stamina, and emotional intelligence to be successful in this demanding specialty? I do not believe there is a perfect predictive formula. Just this last fall, at the annual meeting of the Congenital Heart Surgeons' Society, Dr William Norwood received a lifetime achievement award from the society. In his remarks during the award ceremony, Dr Norwood opined that congenital heart surgery may be the most difficult specialty in medicine. Although there is probably no true objective measure to affirm that opinion, I am inclined to agree with him. Without question, the stakes are at an all-time high in our specialty and our work is under intense scrutiny. Patient and familial expectations are very high (as they should be), and the young surgeon is expected to perform at the highest level right from the start. Our colleagues in pediatric cardiology are under enormous pressure when they refer their patients to us for care, and they expect accessible.

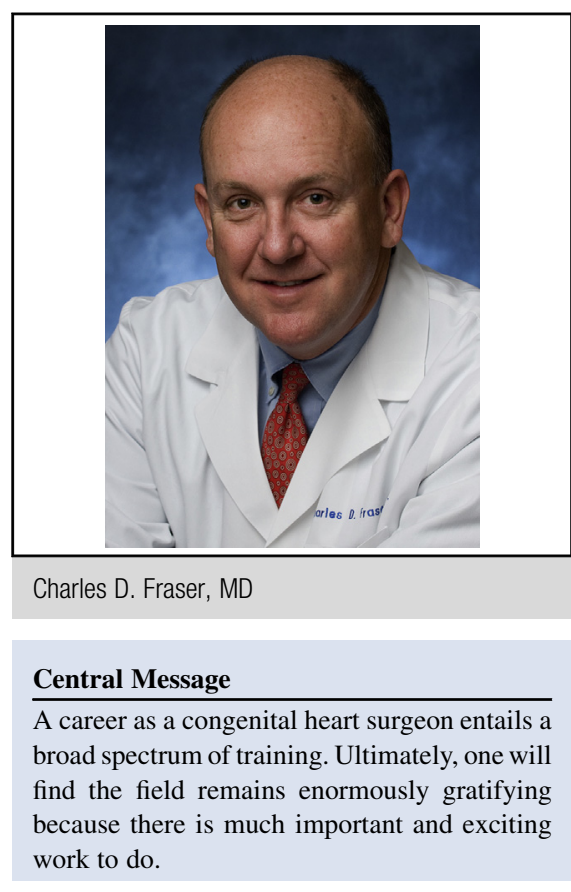

See Article page 1488.

surgical excellence (as they should). The patients are increasingly complex. We are now expected to have near perfect results in situations ranging from the premature or small for gestational age newborn with complex single-ventricle and multisystem anomalies to the multi-reoperation in an advanced-age adult with complex congenital heart disease and multiple comorbidities. Our results are now a matter of public record and widely

In this environment of ever-increasing intensity, however, the field remains enormously gratifying, and there is much important and exciting work to do. As such, the article by Kogon and colleagues ${ }^{1}$ in this month's issue of the Journal is a good "pulse check" on how we are doing in the new era of a formal Accreditation Council for Graduate Medical Education fellowship in congenital heart surgery. As the authors note, before the advent of the recognized fellowship in 2007, education in congenital heart surgery was a highly varied proposition. Training extended across a broad spectrum of experience, yet no consistent dialogue about the basic elements of understanding and performance necessary for practice was well documented. In the current study, Kogon and colleagues ${ }^{1}$ have examined survey data and American Board of Thoracic Surgery (ABTS) 
congenital heart surgery examination certification for all 44 graduates of certified programs in North America. The data are interesting and worthy of careful consideration. Of the 44 graduates, 8 did not respond to the survey (an important observation in and of itself). Information from the ABTS regarding congenital heart surgery board certification reveals that of 44 potentially eligible participants, only 22 $(50 \%)$ have successfully completed the required congenital examination process. This is quite disturbing. Of the $44 \mathrm{fel}-$ lows, 7 have not yet achieved basic ABTS Thoracic Surgery certification and thus are ineligible to sit for their congenital examinations. Of additional concern, the median age at graduation of the fellows' cohort is $\mathbf{4 0}$ years. Of the 36 individuals who responded to the survey, 28 ( $76 \%$ of respondents) are practicing congenital heart surgery. Fellows are predominantly male $(83 \%)$, and $91 \%$ who are practicing congenital heart surgery are in a nonsolo practice environment. The surgical experience of the fellows during the 1year fellowship is varied, but with limited experience in complex neonates. Only $25 \%$ of fellows have experience in nonsurgical rotations (ie, echocardiography, catheterization, intensive care).

These data provide much thought-provoking information. The fact that only $50 \%$ of our candidates have successfully completed the entire process is sobering. Is the bar too high or too low? As noted previously, the field is complex and the demands are high. Our judges are rightfully very critical, and expectations are for near perfection. Is the current fellowship paradigm successful in preparing our future colleagues?

My opinion is that we must continue to refine the process. For one, having a median age of 40 years for graduates is unacceptable. One can imagine the personal and familial burden this translates into, and for a large percentage of aspiring candidates to essentially fail at this advanced age of life is tragic. That only one fourth of the fellows participate in nonsurgical but critically related rotations during their fellowship also is concerning. When does one develop the skills to critically assess diagnostic data, read echocardiograms, and care for critical newborn babies? The antecedent years of general surgery and basic cardiothoracic surgery offer little opportunity to learn these critical elements of the integrated management and care of complex children. Furthermore, although case volumes appear "adequate" in relationship to the requisite 75 index cases, newborn surgical experience is highly limited. This is completely predictable and in many ways probably appropriate. To expect someone to be able to perform complex newborn heart surgery with excellent outcomes in a brand new environment after just learning how to perform adult cardiac surgery is unrealistic.
My primary mentor in pediatric cardiac surgery was Roger B. B. Mee. I well remember my disappointment (and silent resistance) as a fellow when he told me it would be 5 years before I was a fully "fledged" congenital heart surgeon. I now know he was completely correct. As such, it is reassuring to see that the majority of our recent graduates are entering a group practice (predominantly academic settings) where they will have the opportunity for ongoing, gradually increasing responsibility, hopefully in a closely mentored environment. In advising candidates and particularly our own fellows at Texas Children's Hospital, I have emphasized that this is a critical job selection decision to optimize the opportunity for success. I do not believe that any fellow, no matter how talented, should finish the 1 year of formal congenital training and go into solo practice. This is a dangerous recipe with high-risk potential.

Should the current fellowship paradigm be further modified? I sincerely believe so. First, I believe 1 formal year of training is too short. Our colleagues in general pediatric surgery have a 2-year fellowship, and our specialty is every bit as complex as theirs. Are the preparatory years in general surgery and adult cardiothoracic surgery optimal? Probably not if one critically considers the skill set needed in congenital practice. As an example suggestion, it would, in my view, make more sense for the basic ABTS thoracic fellowship to have more latitude in rotations for those individuals who are committed to congenital heart surgery; rotations in the broader fields of pediatrics, neonatal/pediatric critical care, echocardiography, cardiac catheterization, and morphology would be extremely useful. As I have written in other editorials, I also strongly submit that we need to, in some meaningful way, re-embrace our international heritage in congenital heart surgery training. This opportunity can be pivotal for the aspiring congenital heart surgeon. Finally, the evolving congenital heart surgery fellowship must embrace the rapidly expanding and ever more complex field of adult congenital heart surgery with a more formalized experience profile.

Kogon and colleagues ${ }^{1}$ have confirmed that fellowship Accreditation Council for Graduate Medical Education training in congenital heart surgery as the route to ABTS congenital heart surgery certification is off to a reasonable start, but there is much refinement left to do. As a specialty, we owe it to our fine young surgeon candidates to offer the most robust and fair pathway to success while never compromising on the public trust and patient well-being.

\section{Reference}

1. Kogon B, Karamlou T, Baumgartner W, Merrill W, Backer C. Congenital cardiac surgery fellowship training: a status update. J Thorac Cardiovasc Surg. 2016;151:1488-95. 